\title{
A core-shell catalyst design boosts the performance of photothermal reverse water gas shift catalysis
}

\author{
Deyue Lou ${ }^{1 \dagger}$, Zhijie $\mathrm{Zhu}^{1 \dagger}$, Yang-Fan $\mathrm{Xu}^{2 \dagger}$, Chaoran $\mathrm{Li}^{{ }^{1}}{ }^{*}$, Kai Feng ${ }^{1}$, Dake Zhang ${ }^{1}$, Kangxiao $\mathrm{Lv}^{1}$, \\ Zhiyi $\mathrm{Wu}^{1}$, Chengcheng Zhang ${ }^{1}$, Geoffrey A. Ozin ${ }^{2 *}$, Le $\mathrm{He}^{{ }^{*}}$ and Xiaohong Zhang
}

\begin{abstract}
Photothermal reverse water gas shift (RWGS) catalysis holds promise for efficient conversions of greenhouse gas $\mathrm{CO}_{2}$ and renewable $\mathrm{H}_{2}$, powered solely by sunlight, into $\mathrm{CO}$, an important feedstock for the chemical industry. However, the performance of photothermal RWGS catalysis over existing supported catalysts is limited by the balance between the catalyst loading and dispersity, as well as stability against sintering. Herein, we report a core-shell strategy for the design of photothermal catalysts, by using $\mathrm{Ni}_{12} \mathrm{P}_{5}$ as an example, with simultaneously strong light absorption ability, high dispersity and stability. The core-shell structured $\mathrm{Ni}_{12} \mathrm{P}_{5} @ \mathrm{SiO}_{2}$ catalyst with a relatively small $\mathrm{Ni}_{12} \mathrm{P}_{5}$ particle size of $15 \mathrm{~nm}$ at a high $\mathrm{Ni}_{12} \mathbf{P}_{5}$ loading of $30 \mathrm{wt} \%$ exhibits improved activity, nearly $100 \%$ CO selectivity, and superior stability in photothermal RWGS catalysis, particularly under intense illuminations. Our study clearly reveals the effectiveness of the core-shell strategy in breaking the limitation of supported catalysts and boosting the performance of photothermal $\mathrm{CO}_{2}$ catalysis.
\end{abstract}

Keywords: photothermal catalysis, RWGS, nickel phosphide, core-shell structure

\section{INTRODUCTION}

The conversion of $\mathrm{CO}_{2}$ and renewable $\mathrm{H}_{2}$ into fuels and feedstock chemicals through heterogeneous photocatalysis is a promising solution to sustainable energy security and global climate change [1-8]. Among different solar-powered $\mathrm{CO}_{2}$ hydrogenation processes, photothermal reverse water gas shift (RWGS) catalysis features the operation under ambient conditions and powered solely by sunlight to convert $\mathrm{CO}_{2}$ into $\mathrm{CO}$, an important feedstock for the chemical industry [9-16]. For example, $\mathrm{CO}$ can be transformed into different liquid fuels (diesel, gasoline, and alcohols) through further hydrogenation $[17,18]$. Compared with direct hydrogenation of $\mathrm{CO}_{2}$ to produce value-added methanol, the $\mathrm{CO}$ hydrogenation process is more thermodynamically favorable to achieve a much higher yield [19-21]. Through the endothermic RWGS reaction, solar energy is transformed into chemical energy with the ease of large-scale storage and transportation [22,23].

Since the pioneering study by Meng et al. [24] in 2014, many attempts have been made in the development of efficient catalysts, mainly based on supported metal nanoparticles, for photothermal $\mathrm{CO}_{2}$ hydrogenation reactions [25-32]. However, the performance of supported catalysts in photothermal RWGS catalysis is generally limited by the balance between the metal loading (determining the light absorption ability and photothermal performance) and dispersity (determining the intrinsic catalytic performance), as well as stability against sintering. To ensure strong absorption of the solar spectrum, the metal loading is typically high and thus the size of metal nanoparticles is quite large [24,32]. These largesized nanoparticles with low atom efficiency (dispersion) suffer from poor intrinsic catalytic activity and/or selectivity. The selectivity of CO production through the RWGS process in most studies is quite low because the competing Sabatier reaction is more favorable over largesized metal nanoparticles [33-38]. A few catalysts exhibited very high $\mathrm{CO}$ selectivity in photothermal $\mathrm{CO}_{2}$ catalysis but still suffered from poor activity and/or stability [39-44]. Very recently, we discovered that transition metal phosphide (such as $\mathrm{Ni}_{12} \mathrm{P}_{5}$ ) nanoparticles supported on silica could catalyze the photothermal RWGS reaction with a robust near-unity $\mathrm{CO}$ selectivity

\footnotetext{
${ }^{1}$ Institute of Functional Nano \& Soft Materials (FUNSOM), Jiangsu Key Laboratory for Carbon-Based Functional Materials \& Devices, Soochow University, Suzhou 215123, China

${ }^{2}$ Solar Fuels Group, Department of Chemistry, University of Toronto, Toronto, Ontario M5S 3H6, Canada

† These authors contributed equally to this work.

* Corresponding authors (emails: crli@suda.edu.cn (Li C); gozin@chem.utoronto.ca (Ozin G); lehe@suda.edu.cn (He L))
} 
[45]. Nevertheless, the performance of $\mathrm{Ni}_{12} \mathrm{P}_{5}$ in photothermal RWGS catalysis is still limited by the trade-off between the catalyst loading and dispersity. Therefore, it is highly desired but challenging to improve the performance of photothermal RWGS catalysis by breaking the limitation of supported catalysts.

In this study, we report a core-shell strategy that enables the design of photothermal catalysts simultaneously with strong light absorption ability, high dispersity and stability. By using $\mathrm{Ni}_{12} \mathrm{P}_{5}$ as an example, we demonstrate that the core-shell design increases $\mathrm{Ni}_{12} \mathrm{P}_{5}$ loading to 30 wt $\%$ while maintaining a relatively small $\mathrm{Ni}_{12} \mathrm{P}_{5}$ particle size of $15 \mathrm{~nm}$ even at temperatures above $600^{\circ} \mathrm{C}$. The core-shell $\mathrm{Ni}_{12} \mathrm{P}_{5} @ \mathrm{SiO}_{2}$ catalyst exhibits improved activity, nearly $100 \%$ CO selectivity, and superior stability in photothermal RWGS catalysis, particularly under intense illuminations.

\section{EXPERIMENTAL SECTION}

\section{Materials}

All chemicals were used as received without further purification. Oleylamine (OAm, 80\%-90\%), nickel(II) acetylacetonate $\left(\mathrm{Ni}(\mathrm{acac})_{2}, 95 \%\right)$, and trioctylphosphine (TOP, $>90 \%$ ) were purchased from Aladdin. Ammonium hydroxide $\left(\mathrm{NH}_{3} \cdot \mathrm{H}_{2} \mathrm{O}, 28 \mathrm{wt} \%\right)$ and Igepal $\mathrm{CO}-520$ were obtained from Mackin Biochemical (Shanghai) Co., Ltd. Tetraethyl orthosilicate (TEOS) was purchased from TCI (Shanghai) development Co., Ltd. Nickel nitrate, ammonium phosphate $\left(\left(\mathrm{NH}_{4}\right)_{2} \mathrm{HPO}_{4}\right)$, ethanol and hexane were obtained from Sinopharm Chemical Reagent Co., Ltd. Continuous carbon support film and holey carbon support film were obtained from Zhongjingkeyi (Beijing) Film Technology Co., Ltd. Milli-Q water (Millipore, $18.2 \mathrm{M} \Omega \mathrm{cm}$ at $25^{\circ} \mathrm{C}$ ) was used in all experiments.

\section{Synthesis of $\mathrm{SiO}_{2}$-supported $\mathrm{Ni}_{12} \mathrm{P}_{5}$}

$\mathrm{Ni}_{12} \mathrm{P}_{5}$ nanoparticles were prepared through the same method reported in our previous study [45]. In a typical synthesis, nickel nitrate and $\left(\mathrm{NH}_{4}\right)_{2} \mathrm{HPO}_{4}$ with the molar ratio of 12:5 were first dissolved in deionized water to form the precursor solution. $\mathrm{SiO}_{2}$ supports were then added into the solution. After being dried at $120^{\circ} \mathrm{C}$, the precursor containing $\mathrm{SiO}_{2}$ supports was annealed in air at $550^{\circ} \mathrm{C}$ for $6 \mathrm{~h}$, and then reduced under flowing $10 \% \mathrm{H}_{2} /$ Ar at $600^{\circ} \mathrm{C}$ for $6 \mathrm{~h}$.

\section{Preparation of $\mathrm{Ni}_{12} \mathrm{P}_{5} @ \mathrm{SiO}_{2}$}

In a typical synthesis of $\mathrm{Ni}_{12} \mathrm{P}_{5}$ nanocrystals, $\mathrm{Ni}(\mathrm{acac})_{2}$ $(2.00 \mathrm{~g})$ was dissolved to the mixture solution of OAm
$(20.8 \mathrm{~g})$ and TOP $(2.30 \mathrm{~g})$. The reaction mixture was then heated to $220^{\circ} \mathrm{C}$ and kept under $\mathrm{N}_{2}$ protection for $2 \mathrm{~h}$. After cooling down to room temperature, $30 \mathrm{~mL}$ of hexane and ethanol $(v / v=1 / 1)$ was added into the solution and the black products were collected by centrifugation, cleaned twice with hexane and ethanol, and then dispersed in $\sim 10 \mathrm{~mL}$ of hexane to reach a concentration of $50 \mathrm{mg} \mathrm{mL}^{-1}$ [46]. A layer of silica was then coated on the surface of the as-obtained $\mathrm{Ni}_{12} \mathrm{P}_{5}$ nanocrystals through a reverse microemulsion method. Briefly, $20 \mathrm{~g}$ of Igepal CO-520 was dissolved in $110 \mathrm{~mL}$ of cyclohexane under ultrasonication for $30 \mathrm{~min}$, followed by the addition of $1 \mathrm{~mL}$ of the hexane dispersion of $\mathrm{Ni}_{12} \mathrm{P}_{5}$ nanocrystals $(50 \mathrm{mg})$. After stirring for $4 \mathrm{~h}, 1.0 \mathrm{~mL}$ of TEOS and $0.4 \mathrm{~mL}$ of $\mathrm{NH}_{3} \cdot \mathrm{H}_{2} \mathrm{O}$ were added into the reaction. After stirring for additional $8 \mathrm{~h}$, the products were collected by centrifugation, cleaned with ethanol for several times, and dried naturally. Finally, the as-obtained black powder was calcined in air at $400^{\circ} \mathrm{C}$ for $2 \mathrm{~h}$ to remove organic contaminants, followed by the reduction by $\mathrm{H}_{2}$ in a tube furnace at $400^{\circ} \mathrm{C}$ for $2 \mathrm{~h}$.

\section{Characterization}

Transmission electron microscopy (TEM) images were obtained with an FEI-Tecnai F20 $(200 \mathrm{kV})$ transmission electron microscope. Powder X-ray diffraction (XRD) patterns were recorded on an Empyrean diffractometer with a $\mathrm{Cu} \mathrm{Ka}$ radiation. The loadings of $\mathrm{Ni}_{12} \mathrm{P}_{5}$ in different samples were measured by an inductively coupled plasma source mass spectrometer (ICP-MS, Aurora M90, Jenoptik). Diffuse reflectance spectra were obtained using a Lambda 950 UV/VIS/NIR spectrometer from Perkin Elmer equipped with an integrating sphere with a diameter of $150 \mathrm{~mm}$.

\section{Catalytic testing}

Photothermal catalytic $\mathrm{CO}_{2}$ hydrogenation experiments were performed in a home-made flow reactor (Reactor I, Fig. S1). The reactor was equipped with a circular quartz window $(r=2.75 \mathrm{~cm})$ to allow illumination from the top. A 300-W Xe arc lamp was used to illuminate the catalysts without any filter. The flow rates of feeding gases were fixed at $5 \mathrm{~mL} \mathrm{~min}^{-1}$ for $\mathrm{CO}_{2}, 5 \mathrm{~mL} \mathrm{~min}^{-1}$ for $\mathrm{H}_{2}$, and $10 \mathrm{~mL} \mathrm{~min}^{-1}$ for $\mathrm{N}_{2}$. The inner volume of the reactor is $6.2 \mathrm{~cm}^{3}$. The pressure of the reactor was monitored by a digital pressure gauge from ANCN Smart Instrument Inc. Reactor I can be heated up to $450^{\circ} \mathrm{C}$. For each test, $\sim 10 \mathrm{mg}$ of catalysts were used.

Thermocatalytic steady-state $\mathrm{CO}_{2}$ hydrogenation was also performed in a quartz tube flow reactor with an inner 
diameter of $4 \mathrm{~mm}$ (Reactor II, Fig. S2) under atmospheric pressure. The catalyst $(30 \mathrm{mg})$ was loaded into the reactor tube and held in place by quartz wool for each test. The flow rates of feeding gases were fixed at $5 \mathrm{~mL} \mathrm{~min}^{-1}$ for $\mathrm{CO}_{2}, 5 \mathrm{~mL} \min ^{-1}$ for $\mathrm{H}_{2}$, and $10 \mathrm{~mL} \mathrm{~min}^{-1}$ for $\mathrm{N}_{2}$. The amounts of gas reactants and products were analyzed by a thermal conductivity detector (TCD) and a flame ionization detector (FID) with a convertor installed in a gas chromatography (Agilent 7890B). Reactor II can be heated up to $900^{\circ} \mathrm{C}$.

\section{RESULTS AND DISCUSSION}

Monodisperse $\mathrm{Ni}_{12} \mathrm{P}_{5}$ nanoparticles with the average diameter of $15 \mathrm{~nm}$ were first synthesized through a wetchemistry method (Fig. S3). A thin silica layer with the thickness of $12 \mathrm{~nm}$ was subsequently coated on individual $\mathrm{Ni}_{12} \mathrm{P}_{5}$ nanoparticles (Fig. 1a, b). The core-shell design increases the loading of $\mathrm{Ni}_{12} \mathrm{P}_{5}$ to $30 \mathrm{wt} \%$ while maintaining a relatively small size of $15 \mathrm{~nm}$ (Table 1). Elemental mapping results confirmed the expected distributions of different elements in the as-obtained core-shell structured $\mathrm{N}_{12} \mathrm{P}_{5} @ \mathrm{SiO}_{2}$ nanoparticles (Fig. 1cg). Fig. $1 \mathrm{~h}$ depicts the XRD pattern of $\mathrm{N}_{12} \mathrm{P}_{5} @ \mathrm{SiO}_{2}$ and the peaks match well with tetragonal phase $\mathrm{Ni}_{12} \mathrm{P}_{5}$ (JCPDS 22-1190). The core-shell structure exhibited a strong broadband absorption of solar spectrum (Fig. 1i).

For comparison studies, two silica-supported $\mathrm{Ni}_{12} \mathrm{P}_{5}$ nanoparticles with the loading of $8 \mathrm{wt} \%$ and $15 \mathrm{wt} \%$, denoted as SP-1 and SP-2, respectively, were prepared through the wetness impregnation method adapted from
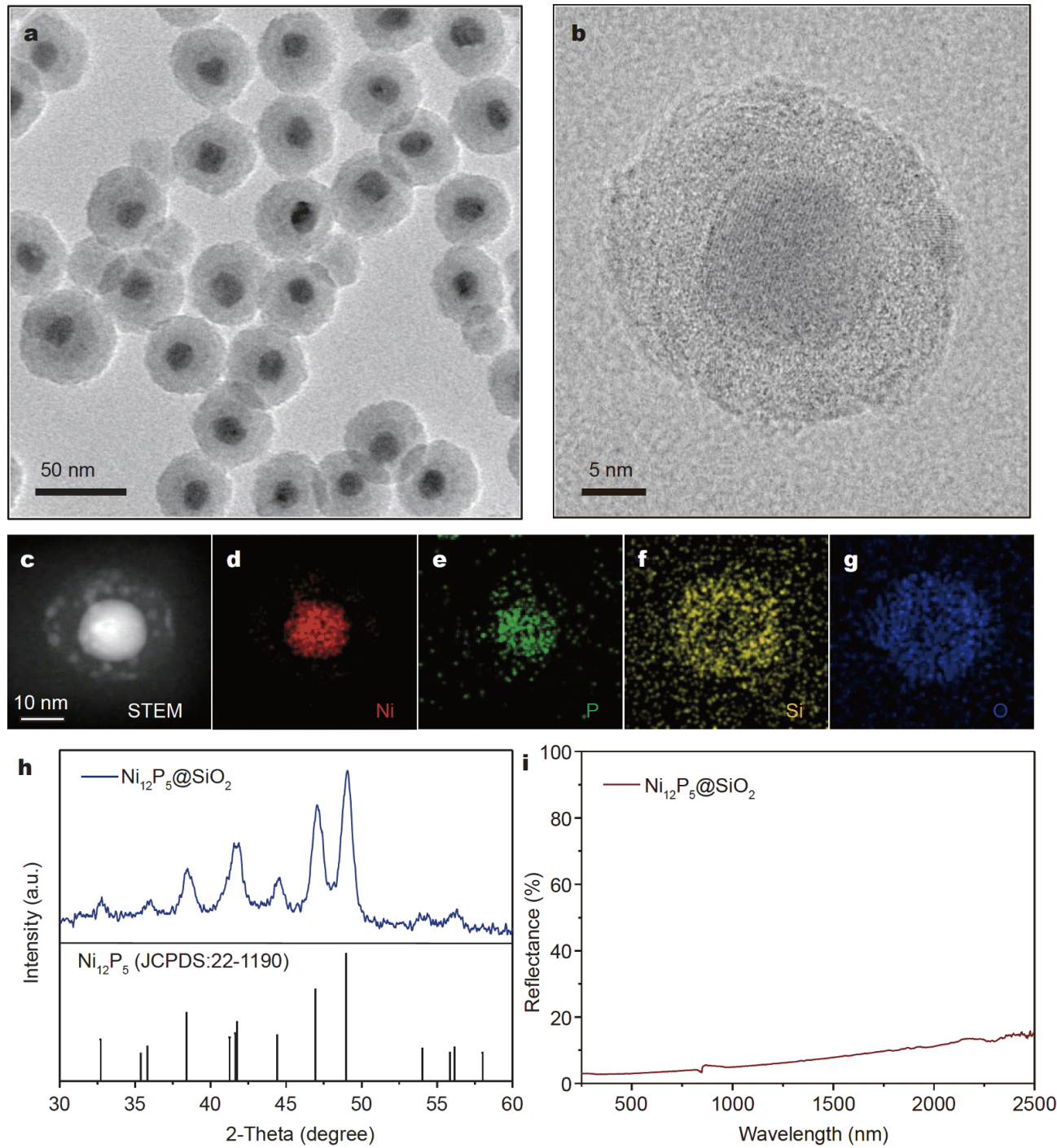

Figure 1 (a, b) TEM images, (c-g) EDS elemental mapping images, (h) XRD pattern, and (i) diffuse reflectance spectrum of $\mathrm{Ni}_{12} \mathrm{P}_{5} @ \mathrm{SiO}_{2}$. 
our previous study [45]. Fig. S4 shows the TEM images of the $8 \mathrm{wt} \%$ sample. The average size of $\mathrm{Ni}_{12} \mathrm{P}_{5}$ nanocrystals was found to be $11 \mathrm{~nm}$ (Fig. S5). The particle size increased to $19 \mathrm{~nm}$ for SP-2 that is even larger than that of $\mathrm{N}_{12} \mathrm{P}_{5} @ \mathrm{SiO}_{2}$ with a higher loading of $30 \mathrm{wt} \%$ (Figs S6 and S7, Table 1). XRD studies confirmed the formation of tetragonal phase $\mathrm{Ni}_{12} \mathrm{P}_{5}$ (Fig. S8). Owing to their lower $\mathrm{Ni}_{12} \mathrm{P}_{5}$ loading, the as-obtained silica-supported $\mathrm{Ni}_{12} \mathrm{P}_{5}$ nanoparticles exhibited weaker sunlight absorption ability than the core-shell structure (Fig. S9).

The performance of different $\mathrm{Ni}_{12} \mathrm{P}_{5}$ catalysts in photothermal RWGS catalysis was investigated in a flow-type photoreactor at atmospheric pressure (Reactor I, Fig. S1). No additional external heating was applied. The feeding ratio of $\mathrm{CO}_{2}: \mathrm{H}_{2}: \mathrm{N}_{2}$ was kept at 1:1:2 while varying the light intensity from 2.0 to $4.0 \mathrm{~W} \mathrm{~cm}^{-2}$. CO was detected as the major product with selectivity over $98 \%$ under different illumination conditions for all catalysts (Figs S10 and S11).

The effect of light intensity on the performance of SP-1 was first discussed. As expected, the $\mathrm{CO}$ production rate, $R_{\mathrm{CO}}$, increased with the light intensity owing to higher catalyst temperatures under stronger illuminations (Fig. 2a). Specifically, the initial CO rates (normalized by the mass of $\mathrm{Ni}_{12} \mathrm{P}_{5}$ ) of SP-1 were found to be $14 \mathrm{mmol} \mathrm{g}_{\text {cat }}{ }^{-1} \mathrm{~h}^{-1}$ for $2.0 \mathrm{~W} \mathrm{~cm}{ }^{-2}, 75 \mathrm{mmol} \mathrm{g}_{\text {cat }}^{-1} \mathrm{~h}^{-1}$ for $3.0 \mathrm{~W} \mathrm{~cm}^{-2}$, and $128 \mathrm{mmol} \mathrm{g}_{\text {cat }}^{-1} \mathrm{~h}^{-1}$ for $4.0 \mathrm{~W} \mathrm{~cm}^{-2}$
(Fig. 2a). However, the photocatalytic performance decayed obviously within one hour of testing under strong illumination conditions, particularly for $4.0 \mathrm{~W} \mathrm{~cm}^{-2}$. Despite a stable CO selectivity, a decline of $R_{\mathrm{CO}}$ by $\sim 60 \%$ was observed in a continuous $10-\mathrm{h}$ run under $4.0 \mathrm{~W} \mathrm{~cm}^{-2}$ (Fig. 2b, Table 1). TEM images and the XRD pattern of the spent SP-1 sample revealed that the size of $\mathrm{Ni}_{12} \mathrm{P}_{5}$ nanoparticles increased from 11 to $18 \mathrm{~nm}$ with no obvious change in chemical composition (Figs S12 and S13). The sintering of catalyst particles reduced the number of active sites, which is responsible for the performance decay under reaction conditions.

It is well known that smaller nanoparticles possess higher surface free energy and lower Tammann temperatures, leading to a stronger tendency of agglomeration [47-49]. However, it was found that the stability of SP-2 under photothermal catalytic conditions was mildly improved but at the expense of decreased activity. Similar to that of SP-1, the $R_{\mathrm{CO}}$ of SP-2 increased with the light intensity increasing from 2.0 to $4.0 \mathrm{~W} \mathrm{~cm}^{-2}$ (Fig. 2a). Under the same intensities, the activity of SP-2 was found to be rather lower than that of SP-1. This can be explained by the presence of fewer active sites in SP-2 for the photothermal RWGS reaction. While the stability of SP-2 is slightly enhanced under $3.0 \mathrm{~W} \mathrm{~cm}^{-2}$, the drop of performance due to particle sintering was clearly observed under $4.0 \mathrm{~W} \mathrm{~cm}^{-2}$ (Fig. 2a, b). After testing for

Table 1 Properties and photothermal performance of $\mathrm{Ni}_{12} \mathrm{P}_{5}$ under $4.0 \mathrm{~W} \mathrm{~cm}{ }^{-2}$

\begin{tabular}{|c|c|c|c|c|c|c|}
\hline Sample & $\mathrm{Ni}_{12} \mathrm{P}_{5}(\mathrm{wt} \%)$ & $D_{0}{ }^{\mathrm{a}}(\mathrm{nm})$ & $D_{10 \mathrm{~h}}{ }^{\mathrm{b}}(\mathrm{nm})$ & $R_{0}{ }^{\mathrm{c}}$ & $R_{10 \mathrm{~h}}{ }^{\mathrm{d}}$ & Rate drop (\%) \\
\hline SP-1 & 8 & 11 & 18 & 128 & 52 & 58 \\
\hline SP-2 & 15 & 19 & 32 & 48 & 23 & 52 \\
\hline $\mathrm{Ni}_{12} \mathrm{P}_{5} @ \mathrm{SiO}_{2}$ & 30 & 15 & 15 & 135 & 134 & $<1$ \\
\hline
\end{tabular}

a) The initial size of $\mathrm{Ni}_{12} \mathrm{P}_{5}$ particles. b) The size of $\mathrm{Ni}_{12} \mathrm{P}_{5}$ after testing for $10 \mathrm{~h}$. c) The initial CO rate with the unit of mmol gcat ${ }^{-1} \mathrm{~h}^{-1}$. d) The CO rate at $10 \mathrm{~h}$ with the unit of $\mathrm{mmol} \mathrm{g}_{\text {cat }}{ }^{-1} \mathrm{~h}^{-1}$.
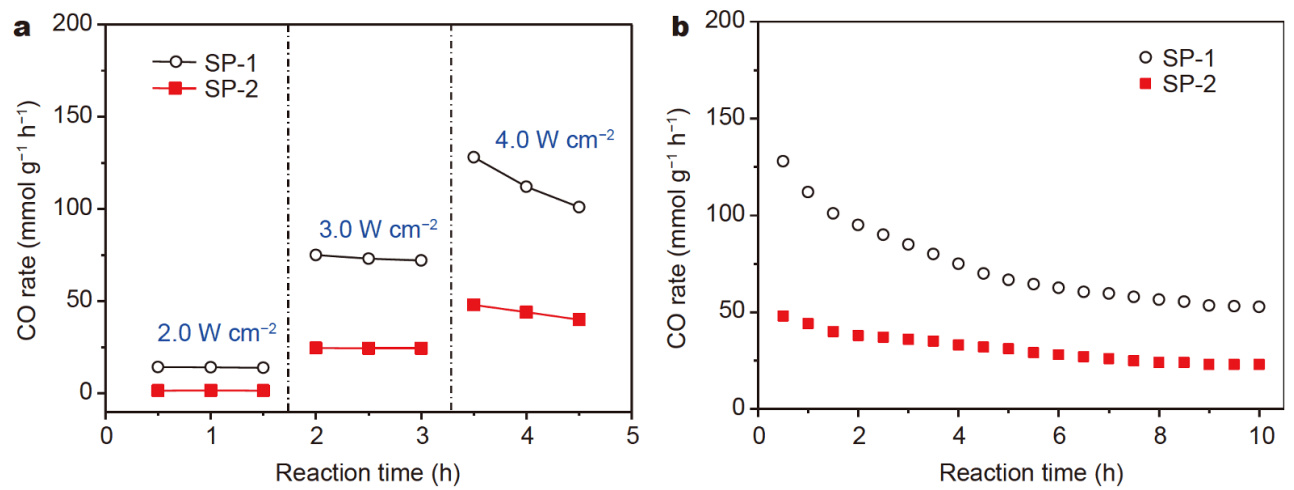

Figure 2 (a) Intensity-dependent activities of SP-1 and SP-2 in photothermal RWGS catalysis. (b) Time-dependent activities of SP-1 and SP-2 in a continuous 10 -h run of photothermal catalytic testing under the $4.0 \mathrm{~W} \mathrm{~cm}^{-2}$ illumination. 
$10 \mathrm{~h}$, the activity of SP-2 dropped by $50 \%$ to $23 \mathrm{mmol} \mathrm{g}{ }_{\text {cat }}^{-1} \mathrm{~h}^{-1}$ along with increase of $\mathrm{Ni}_{12} \mathrm{P}_{5}$ particle size from 19 to $32 \mathrm{~nm}$ (Fig. 2b, Table 1).

To further demonstrate the poor stability of the supported $\mathrm{Ni}_{12} \mathrm{P}_{5}$ catalysts at high temperatures, we also tested their thermocatalytic performances under dark conditions in a quartz tube flow reactor (Reactor II, Fig. S2). SP-1 exhibited higher activity than SP-2 under the same conditions, which can be attributed to more active sites for the former (Fig. 3a). Despite the stable CO selectivity of over $98 \%$ at $300-600^{\circ} \mathrm{C}$, both samples exhibited an obvious decline in the $\mathrm{CO}$ rate with time under the testing conditions of above $400^{\circ} \mathrm{C}$ (Fig. 3). The poor stability of the supported $\mathrm{Ni}_{12} \mathrm{P}_{5}$ catalysts against sintering would limit the improvement of photothermal catalytic performance by raising the light intensity.

Compared with the silica-supported $\mathrm{Ni}_{12} \mathrm{P}_{5}$ catalysts, the core-shell structure exhibited an enhanced activity and stability in photothermal RWGS catalysis. The initial catalytic activity of $\mathrm{Ni}_{12} \mathrm{P}_{5} @ \mathrm{SiO}_{2}$ was higher than those of SP-1 and SP-2 under the same illumination conditions

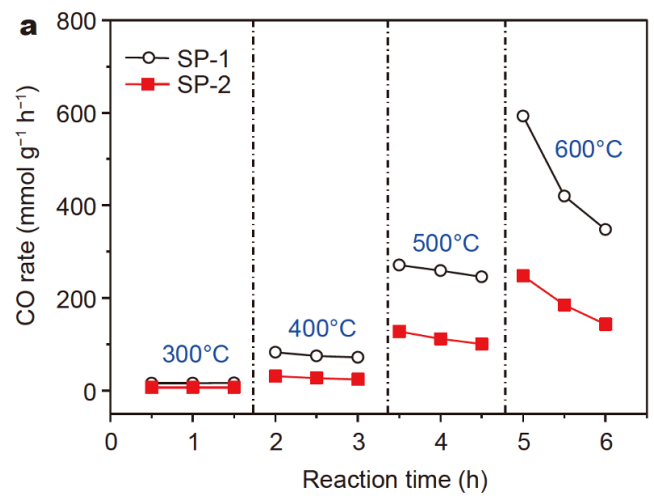

(Fig. S14). More importantly, no obvious performance decay was observed for $\mathrm{Ni}_{12} \mathrm{P}_{5} @ \mathrm{SiO}_{2}$ under all tested conditions (Fig. 4a). Distinct from SP-1 and SP-2, the core-shell structure exhibited a nearly constant rate in the continuous 10-h testing under $4.0 \mathrm{~W} \mathrm{~cm}^{-2}$ (Fig. 4b). After $10 \mathrm{~h}$, the stabilized activity of $\mathrm{Ni}_{12} \mathrm{P}_{5} @ \mathrm{SiO}_{2}$ under $4.0 \mathrm{~W} \mathrm{~cm}^{-2}$ was 2.6 and 5.8 times as high as those of SP-1 and SP-2, respectively (Table 1 ). Both XRD and TEM studies revealed that the size and composition of encapsulated $\mathrm{Ni}_{12} \mathrm{P}_{5}$ nanoparticles kept unchanged under the testing conditions (Figs S15 and S16). These results clearly reveal that the core-shell engineering could enhance the structural stability of $\mathrm{Ni}_{12} \mathrm{P}_{5}$ nanoparticles and thereby their photothermal catalytic performances under intense illuminations.

The excellent stability of the core-shell catalyst was further demonstrated in thermocatalytic tests in Reactor II under dark conditions. $\mathrm{Ni}_{12} \mathrm{P}_{5} @ \mathrm{SiO}_{2}$ exhibited very stable activity and selectivity at $300-600^{\circ} \mathrm{C}$ (Fig. 5a). Moreover, no obvious drop in the activity or selectivity was observed for the core-shell structure in a continuous

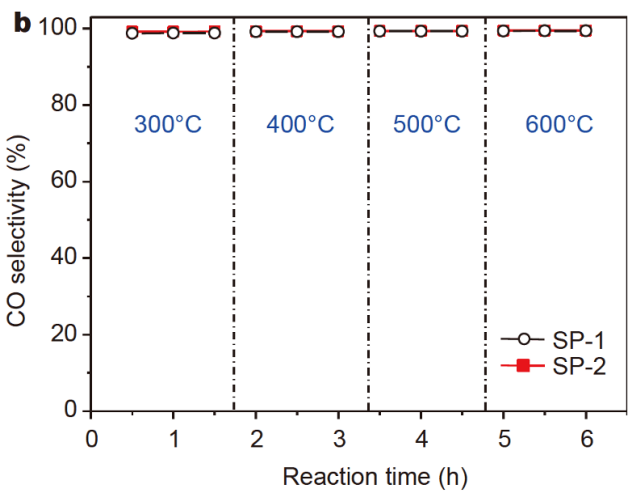

Figure 3 (a) Temperature-dependent performances and (b) CO selectivities of SP-1 and SP-2 in thermocatalytic $\mathrm{CO}_{2}$ hydrogenation under dark conditions.
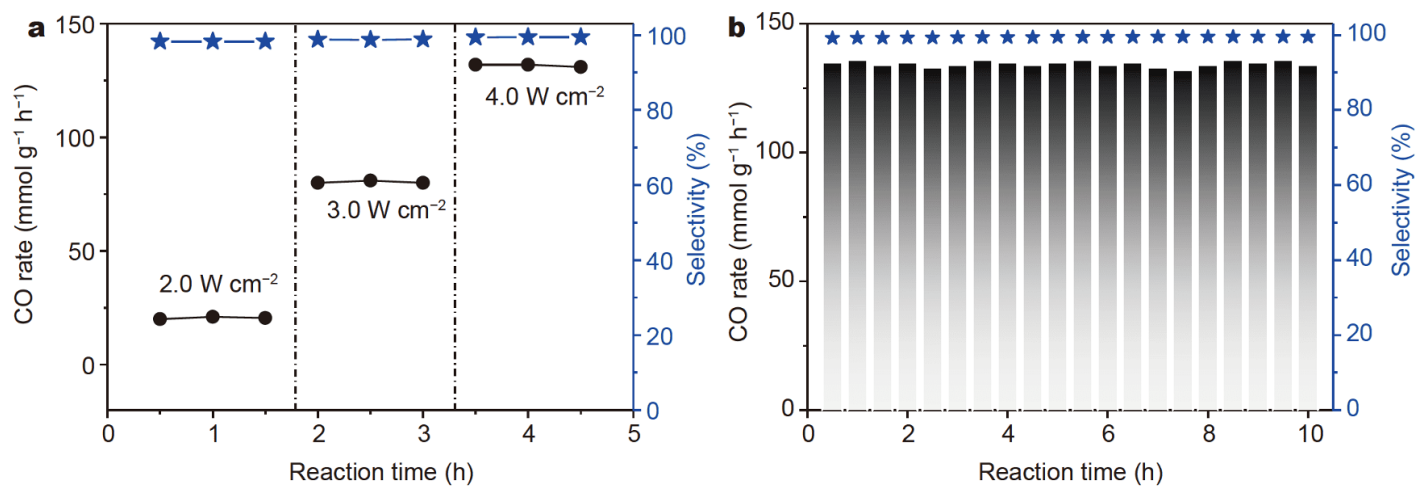

Figure 4 Performance of core-shell $\mathrm{Ni}_{12} \mathrm{P}_{5} @ \mathrm{SiO}_{2}$ in photothermal RWGS catalysis (a) under different light intensities and (b) in a continuous 10-h run under $4.0 \mathrm{~W} \mathrm{~cm}^{-2}$. 

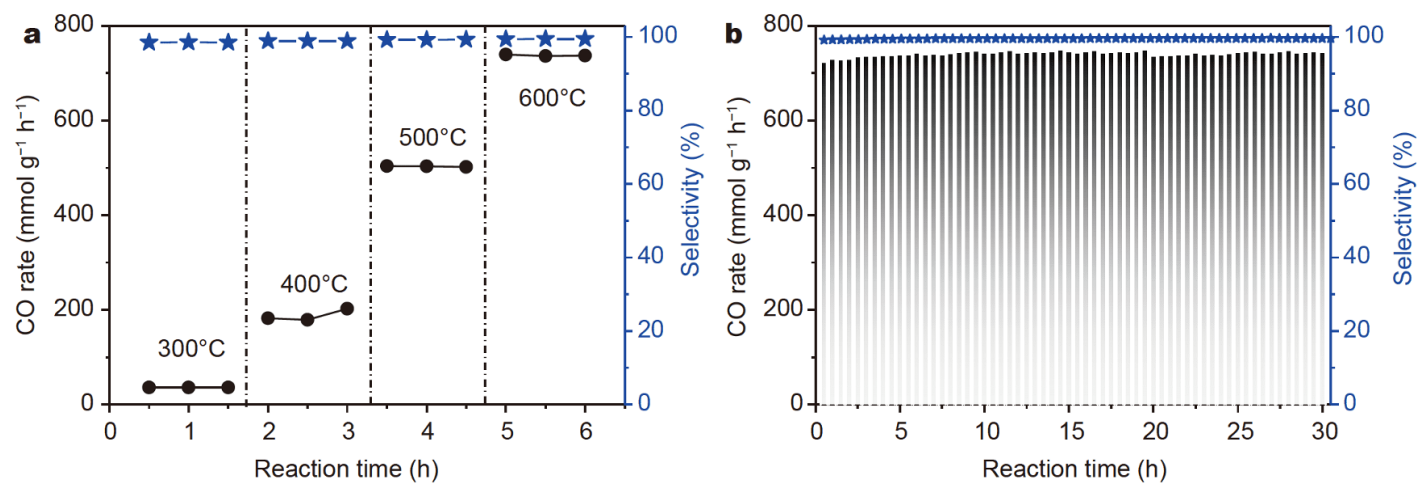

Figure 5 Performance of $\mathrm{Ni}_{12} \mathrm{P}_{5} @ \mathrm{SiO}_{2}$ in thermocatalysis (a) at different temperatures and (b) in a continuous 30 -h run at $600^{\circ} \mathrm{C}$.

run of 30-h thermocatalytic testing at $600^{\circ} \mathrm{C}$ (Fig. 5b). The morphology and particle size were preserved in the tested sample (Fig. S17). Notably, the activity of $\mathrm{Ni}_{12} \mathrm{P}_{5} @$ $\mathrm{SiO}_{2}$ was higher than both of the supported catalysts at all temperatures. We also calculated the $\mathrm{CO}_{2}$ conversion degrees of SP-1, SP-2 and $\mathrm{Ni}_{12} \mathrm{P}_{5} @ \mathrm{SiO}_{2}$. Owing to the highest loading and structural stability of $\mathrm{Ni}_{12} \mathrm{P}_{5} @ \mathrm{SiO}_{2}$, it exhibited higher conversion degrees than the supported catalysts under the same conditions, particularly at high temperatures (Fig. S18). For example, the $\mathrm{CO}_{2}$ conversion of $\mathrm{Ni}_{12} \mathrm{P}_{5} @ \mathrm{SiO}_{2}$ catalyst reached $30 \%$ at $600^{\circ} \mathrm{C}$, much higher than those of SP-1 (12\%) and SP-2 (5\%).

To estimate the local temperature of $\mathrm{Ni}_{12} \mathrm{P}_{5}$ under illuminations, the thermocatalytic activity of $\mathrm{Ni}_{12} \mathrm{P}_{5} @ \mathrm{SiO}_{2}$ under dark conditions was also measured in Reactor I at temperatures ranging from 200 to $450^{\circ} \mathrm{C}$. In this study, the equivalent working temperature of photothermal catalysis, $T_{\mathrm{e}}$, is defined as the temperature when the activity in thermocatalysis reaches the same as that under the specific illumination without applying the external heating. $T_{\mathrm{e}}$ were found to be $295^{\circ} \mathrm{C}$ for $2.0 \mathrm{~W} \mathrm{~cm}^{-2}, 391^{\circ} \mathrm{C}$ for $3.0 \mathrm{~W} \mathrm{~cm}^{-2}$, and $426^{\circ} \mathrm{C}$ for $4.0 \mathrm{~W} \mathrm{~cm}^{-2}$ (Fig. S19). Since the core-shell catalyst is stable even at $600^{\circ} \mathrm{C}$, there is plenty of room for further improving the photothermal catalytic performance of $\mathrm{Ni}_{12} \mathrm{P}_{5} @ \mathrm{SiO}_{2}$ by using even stronger light illuminations.

One of the distinguishing features of $\mathrm{Ni}_{12} \mathrm{P}_{5}$ catalysts is the robust near-unity $\mathrm{CO}$ selectivity that is independent of, among other parameters, the $\mathrm{CO}_{2} / \mathrm{H}_{2}$ feeding ratio. To demonstrate the similar property of $\mathrm{Ni}_{12} \mathrm{P}_{5} @ \mathrm{SiO}_{2}$, we investigate the effect of the $\mathrm{CO}_{2} / \mathrm{H}_{2}$ feeding ratio in the range of 1:5 to $5: 1$ on its photothermal catalytic performance under different light intensities. Similar to the supported $\mathrm{Ni}_{12} \mathrm{P}_{5}$ catalysts, the core-shell structure exhibited changing rates but constantly high $\mathrm{CO}$ selectivity under conditions of different $\mathrm{CO}_{2} / \mathrm{H}_{2}$ ratios and illuminations (Figs S20 and S21). This brings more opportunities for further optimizations of the photothermal catalytic performance of $\mathrm{Ni}_{12} \mathrm{P}_{5}$ materials in addition to the structural design demonstrated in the present study.

\section{CONCLUSIONS}

In conclusion, our study reveals that the core-shell structure design not only increases the loading of $\mathrm{Ni}_{12} \mathrm{P}_{5}$ without sacrificing the dispersity, but also enhances the efficiency and stability in photothermal RWGS catalysis, particularly under intense illuminations. While the scope of the present study is focused on the material design, the performance of $\mathrm{Ni}_{12} \mathrm{P}_{5}$ catalysts can be further improved through the optimization of the photoreactor design and testing conditions, as well as deeper understanding of the photothermal catalytic mechanism. Our results also suggest there could be plenty of room for further improving the performance of $\mathrm{Ni}_{12} \mathrm{P}_{5} @ \mathrm{SiO}_{2}$ by using even stronger light illuminations. Our study reveals the importance of catalyst structure in boosting the performance of photothermal $\mathrm{CO}_{2}$ catalysis. The design of metal phosphides photothermal RWGS catalysts with an improved efficiency, nearly $100 \%$ selectivity and long-term stability paves the way for the practical implementation of the solar $\mathrm{CO}_{2}$ refinery.

Received 28 November 2020; accepted 1 February 2021; published online 12 April 2021

1 Ghoussoub M, Xia M, Duchesne PN, et al. Principles of photothermal gas-phase heterogeneous $\mathrm{CO}_{2}$ catalysis. Energy Environ Sci, 2019, 12: 1122-1142

2 Zhao Y, Gao W, Li S, et al. Solar- versus thermal-driven catalysis for energy conversion. Joule, 2019, 3: 920-937

3 Wang L, Zhang W, Zheng X, et al. Incorporating nitrogen atoms 
into cobalt nanosheets as a strategy to boost catalytic activity toward $\mathrm{CO}_{2}$ hydrogenation. Nat Energy, 2017, 2: 869-876

4 Chen G, Waterhouse GIN, Shi R, et al. From solar energy to fuels: recent advances in light-driven $\mathrm{C}_{1}$ chemistry. Angew Chem Int Ed, 2019, 58: 17528-17551

5 Li X, Sun Y, Xu J, et al. Selective visible-light-driven photocatalytic $\mathrm{CO}_{2}$ reduction to $\mathrm{CH}_{4}$ mediated by atomically thin $\mathrm{CuIn}_{5} \mathrm{~S}_{8}$ layers. Nat Energy, 2019, 4: 690-699

6 Qian C, Sun W, Hung DLH, et al. Catalytic $\mathrm{CO}_{2}$ reduction by palladium-decorated silicon-hydride nanosheets. Nat Catal, 2018, 2: $46-54$

7 Kong T, Jiang Y, Xiong Y. Photocatalytic $\mathrm{CO}_{2}$ conversion: What can we learn from conventional $\mathrm{CO}_{x}$ hydrogenation? Chem Soc Rev, 2020, 49: 6579-6591

8 Low J, Zhang L, Zhu B, et al. $\mathrm{TiO}_{2}$ photonic crystals with localized surface photothermal effect and enhanced photocatalytic $\mathrm{CO}_{2}$ reduction activity. ACS Sustain Chem Eng, 2018, 6: 15653-15661

9 Kang L, Liu XY, Wang A, et al. Photo-thermo catalytic oxidation over a $\mathrm{TiO}_{2}-\mathrm{WO}_{3}$-supported platinum catalyst. Angew Chem Int Ed, 2020, 59: 12909-12916

10 Wan $\mathrm{L}$, Zhou Q, Wang $\mathrm{X}$, et al. $\mathrm{Cu}_{2} \mathrm{O}$ nanocubes with mixed oxidation-state facets for (photo)catalytic hydrogenation of carbon dioxide. Nat Catal, 2019, 2: 889-898

11 Robatjazi H, Zhao H, Swearer DF, et al. Plasmon-induced selective carbon dioxide conversion on earth-abundant aluminum-cuprous oxide antenna-reactor nanoparticles. Nat Commun, 2017, 8: 27

12 Jia J, O'Brien PG, He L, et al. Visible and near-infrared photothermal catalyzed hydrogenation of gaseous $\mathrm{CO}_{2}$ over nanostructured Pd@ $\mathrm{Nb}_{2} \mathrm{O}_{5}$. Adv Sci, 2016, 3: 1600189

13 Herron JA, Kim J, Upadhye AA, et al. A general framework for the assessment of solar fuel technologies. Energy Environ Sci, 2015, 8: $126-157$

14 Millet MM, Algara-Siller G, Wrabetz S, et al. Ni single atom catalysts for $\mathrm{CO}_{2}$ activation. J Am Chem Soc, 2019, 141: 2451-2461

15 Guo S, Di J, Chen C, et al. Oxygen vacancy mediated bismuth stannate ultra-small nanoparticle towards photocatalytic $\mathrm{CO}_{2}$-toCO conversion. Appl Catal B-Environ, 2020, 276: 119156

16 Xu F, Meng K, Cheng B, et al. Unique S-scheme heterojunctions in self-assembled $\mathrm{TiO}_{2} / \mathrm{CsPbBr}_{3}$ hybrids for $\mathrm{CO}_{2}$ photoreduction. Nat Commun, 2020, 11: 4613

17 Torres Galvis HM, Bitter JH, Khare CB, et al. Supported iron nanoparticles as catalysts for sustainable production of lower olefins. Science, 2012, 335: 835-838

18 Jiao F, Li J, Pan X, et al. Selective conversion of syngas to light olefins. Science, 2016, 351: 1065-1068

19 Li Z, Liu J, Zhao Y, et al. Co-based catalysts derived from layereddouble-hydroxide nanosheets for the photothermal production of light olefins. Adv Mater, 2018, 30: 1800527

20 Wang Y, Zhao Y, Liu J, et al. Manganese oxide modified nickel catalysts for photothermal co hydrogenation to light olefins. Adv Energy Mater, 2019, 10: 1902860

21 Ma HC, Zhao CC, Chen GJ, et al. Photothermal conversion triggered thermal asymmetric catalysis within metal nanoparticles loaded homochiral covalent organic framework. Nat Commun, 2019, 10: 3368

22 Schneck F, Schendzielorz F, Hatami N, et al. Photochemically driven reverse water-gas shift at ambient conditions mediated by a nickel pincer complex. Angew Chem Int Ed, 2018, 57: 1448214487

23 He Z, Cui M, Qian Q, et al. Synthesis of liquid fuel via direct hydrogenation of $\mathrm{CO}_{2}$. Proc Natl Acad Sci USA, 2019, 116: 1265412659

24 Meng X, Wang T, Liu L, et al. Photothermal conversion of $\mathrm{CO}_{2}$ into $\mathrm{CH}_{4}$ with $\mathrm{H}_{2}$ over group VIII nanocatalysts: An alternative approach for solar fuel production. Angew Chem Int Ed, 2014, 53: 11478-11482

25 Yu F, Wang C, Li Y, et al. Enhanced solar photothermal catalysis over solution plasma activated $\mathrm{TiO}_{2}$. Adv Sci, 2020, 7: 2000204

$26 \mathrm{Li} \mathrm{Y}$, Walsh AG, Li $\mathrm{D}$, et al. W-doped $\mathrm{TiO}_{2}$ for photothermocatalytic $\mathrm{CO}_{2}$ reduction. Nanoscale, 2020, 12: 17245-17252

27 Li Y, Wang C, Song $\mathrm{M}$, et al. $\mathrm{TiO}_{2-x} / \mathrm{CoO}_{x}$ photocatalyst sparkles in photothermocatalytic reduction of $\mathrm{CO}_{2}$ with $\mathrm{H}_{2} \mathrm{O}$ steam. Appl Catal B-Environ, 2019, 243: 760-770

28 Yan J, Wang $\mathrm{C}, \mathrm{Ma} \mathrm{H}$, et al. Photothermal synergic enhancement of direct $\mathrm{Z}$-scheme behavior of $\mathrm{Bi}_{4} \mathrm{TaO}_{8} \mathrm{Cl} / \mathrm{W}_{18} \mathrm{O}_{49}$ heterostructure for $\mathrm{CO}_{2}$ reduction. Appl Catal B-Environ, 2020, 268: 118401

29 Yu F, Wang $\mathrm{C}, \mathrm{Ma} \mathrm{H}$, et al. Revisiting $\mathrm{Pt} / \mathrm{TiO}_{2}$ photocatalysts for thermally assisted photocatalytic reduction of $\mathrm{CO}_{2}$. Nanoscale, 2020, 12: 7000-7010

30 Zhao L, Qi Y, Song L, et al. Solar-driven water-gas shift reaction over $\mathrm{CuO}_{x} / \mathrm{Al}_{2} \mathrm{O}_{3}$ with $1.1 \%$ of light-to-energy Storage. Angew Chem Int Ed, 2019, 58: 7708-7712

31 O'Brien PG, Ghuman KK, Jelle AA, et al. Enhanced photothermal reduction of gaseous $\mathrm{CO}_{2}$ over silicon photonic crystal supported ruthenium at ambient temperature. Energy Environ Sci, 2018, 11: 3443-3451

32 Chen G, Gao R, Zhao Y, et al. Alumina-supported CoFe alloy catalysts derived from layered-double-hydroxide nanosheets for efficient photothermal $\mathrm{CO}_{2}$ hydrogenation to hydrocarbons. Adv Mater, 2018, 30: 1704663

33 Wang L, Wang $\mathrm{Y}$, Cheng $\mathrm{Y}$, et al. Hydrogen-treated mesoporous $\mathrm{WO}_{3}$ as a reducing agent of $\mathrm{CO}_{2}$ to fuels $\left(\mathrm{CH}_{4}\right.$ and $\left.\mathrm{CH}_{3} \mathrm{OH}\right)$ with enhanced photothermal catalytic performance. J Mater Chem A, 2016, 4: 5314-5322

34 Li Y, Hao J, Song H, et al. Selective light absorber-assisted single nickel atom catalysts for ambient sunlight-driven $\mathrm{CO}_{2}$ methanation. Nat Commun, 2019, 10: 2359

35 Feng K, Wang S, Zhang D, et al. Cobalt plasmonic superstructures enable almost $100 \%$ broadband photon efficient $\mathrm{CO}_{2}$ photocatalysis. Adv Mater, 2020, 32: 2000014

36 Jia J, Wang $\mathrm{H}, \mathrm{Lu} \mathrm{Z}$, et al. Photothermal catalyst engineering: hydrogenation of gaseous $\mathrm{CO}_{2}$ with high activity and tailored selectivity. Adv Sci, 2017, 4: 1700252

37 Kong N, Han B, Li Z, et al. Ruthenium nanoparticles supported on $\mathrm{Mg}(\mathrm{OH})_{2}$ microflowers as catalysts for photothermal carbon dioxide hydrogenation. ACS Appl Nano Mater, 2020, 3: 3028-3033

38 Cai MJ, Li CR, He L. Enhancing photothermal $\mathrm{CO}_{2}$ catalysis by thermal insulating substrates. Rare Met, 2020, 39: 881-886

39 Wang L, Dong Y, Yan T, et al. Black indium oxide a photothermal $\mathrm{CO}_{2}$ hydrogenation catalyst. Nat Commun, 2020, 11: 2432

40 He L, Wood TE, Wu B, et al. Spatial separation of charge carriers in $\mathrm{In}_{2} \mathrm{O}_{3-x}(\mathrm{OH})_{y}$ nanocrystal superstructures for enhanced gasphase photocatalytic activity. ACS Nano, 2016, 10: 5578-5586

41 Sun W, Qian C, He L, et al. Heterogeneous reduction of carbon dioxide by hydride-terminated silicon nanocrystals. Nat Commun, 2016, 7: 12553

42 Qi Y, Song L, Ouyang S, et al. Photoinduced defect engineering: Enhanced photothermal catalytic performance of $2 \mathrm{D}$ black $\operatorname{In}_{2} \mathrm{O}_{3-x}$ nanosheets with bifunctional oxygen vacancies. Adv Mater, 2020, 32: 1903915 
43 Hoch LB, O'Brien PG, Jelle A, et al. Nanostructured indium oxide coated silicon nanowire arrays: A hybrid photothermal/photochemical approach to solar fuels. ACS Nano, 2016, 10: 9017-9025

44 Fang Y, Lv K, Li Z, et al. Solution-liquid-solid growth and catalytic applications of silica nanorod arrays. Adv Sci, 2020, 7: 2000310

45 Xu YF, Duchesne PN, Wang L, et al. High-performance lightdriven heterogeneous $\mathrm{CO}_{2}$ catalysis with near-unity selectivity on metal phosphides. Nat Commun, 2020, 11: 5149

46 Wang H, Tang Q, Chen Z, et al. Recent advances on silica-based nanostructures in photocatalysis. Sci China Mater, 2020, 63: 2189_ 2205

47 Ouyang R, Liu JX, Li WX. Atomistic theory of ostwald ripening and disintegration of supported metal particles under reaction conditions. J Am Chem Soc, 2013, 135: 1760-1771

48 Hansen TW, Delariva AT, Challa SR, et al. Sintering of catalytic nanoparticles: Particle migration or ostwald ripening? Acc Chem Res, 2013, 46: 1720-1730

49 Cao XQ, Zhou J, Li S, et al. Ultra-stable metal nano-catalyst synthesis strategy: A perspective. Rare Met, 2020, 39: 113-130

Acknowledgements This work was financially supported by the National Natural Science Foundation of China (51802208, 51920105005, 21902113, 51821002 and 91833303), the Natural Science Foundation of Jiangsu Province (BK20200101), the Collaborative Innovation Centre of Suzhou Nano Science \& Technology, and the Priority Academic Program Development of Jiangsu Higher Education Institutions (PAPD). Ozin G is grateful to the Natural Sciences and Engineering Council of Canada for support of this work.

Author contributions He L, Ozin G, Li C and Zhang X conceived and designed the experiments. Lou $\mathrm{D}, \mathrm{Zhu} \mathrm{Z}$ and $\mathrm{Xu}$ YF carried out the synthesis of materials. Lv K, Zhang D, Wu Z and Zhang C performed the characterizations. Lou D, Zhu Z and Feng $\mathrm{K}$ carried out the catalytic testing. Lou D, Li C, Zhu Z and He L wrote the paper. All the authors contributed to the data analysis, discussed the results, and commented on the manuscript.

Conflict of interest The authors declare that they have no conflict of interest.

Supplementary information Supporting data are available in the online version of the paper.

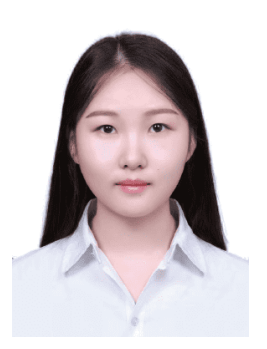

Deyue Lou is currently a Master student at FUNSOM, Soochow University. Her research interest focuses on the photothermal catalytic reduction of carbon dioxide.

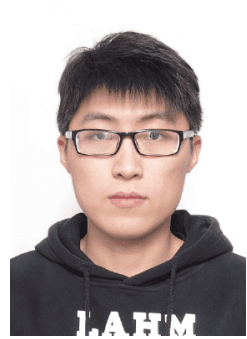

Zhijie Zhu is currently a $\mathrm{PhD}$ student at FUNSOM, Soochow University. His research interest focuses on the photothermal catalytic reduction of carbon dioxide.

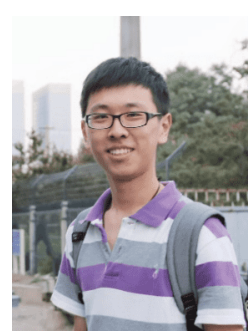

Yang-Fan Xu received his Bachelor and $\mathrm{PhD}$ degrees from Sun Yat-sen University in 2013 and 2018, respectively. He is now a post-doctoral fellow at the University of Toronto, and his current research interest focuses on the lightdriven catalytic $\mathrm{CO}_{2}$ hydrogenation for solar-fuel production.

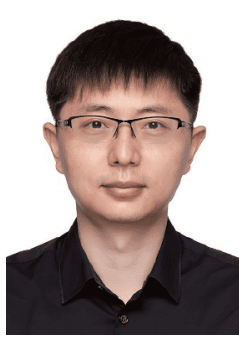

Chaoran Li received his Bachelor's degree from Xiamen University and his doctorate degree from Fujian Institute of Research on the Structure of Matter. From 2015 to 2020, he was a postdoctoral researcher at Soochow University. He then joined FUNSOM, Soochow University, as an associate professor. His research interest focuses on controlled synthesis of low-symmetry nanostructures and their applications in photothermal $\mathrm{CO}_{2}$ reduction.

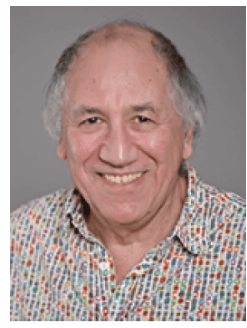

Geoffrey A. Ozin is a Distinguished University Professor at the University of Toronto and the Government of Canada Research Chair in materials chemistry and nanochemistry. He currently spearheads the Solar Fuels Team at the University of Toronto. He has held positions as Honorary Professor at The Royal Institution of Great Britain and University College London, External Adviser for the London Centre for $\mathrm{Na}$ notechnology, Alexander von Humboldt Senior Scientist at the Max Planck Institute for Surface and Colloid Science and the Center for Functional Nanostructures at the Karlsruhe Institute of Technology, and Global Chair at Bath University. 


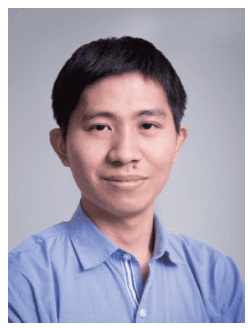

He Le received his Bachelor's degree from Nanjing University and his doctorate degree from the University of California Riverside. From 2013 to 2015, he was a postdoctoral researcher at the University of Toronto, Canada. In 2015, he joined FUNSOM, Soochow University as a professor. His main research interest focuses on the development of functional nanostructured materials for various demanding applications, especially heterogeneous $\mathrm{CO}_{2}$ photocatalysis.

\section{核壳结构增强光热逆水煤气变换催化性能}

娄德月 ${ }^{1 \dagger}$, 朱智杰 ${ }^{1 \dagger}$, 徐杨帆 ${ }^{2 \dagger}$, 李超然 ${ }^{{ }^{*}}$, 冯凯 ${ }^{1}$, 张大科 ${ }^{1}$, 吕康孝 ${ }^{1}$, 吴之怡 ${ }^{1}$, 张城城 ${ }^{1}$, Geoffrey A. Ozin ${ }^{2 *}$, 何乐 ${ }^{1 *}$, 张晓宏 ${ }^{1}$

摘要 光热催化逆水煤气变换有望实现完全太阳能驱动条件下, 将 温室气体 $\mathrm{CO}_{2}$ 和可再生 $\mathrm{H}_{2}$ 转化为重要的化工原料 $\mathrm{CO}$. 然而现有负 载型光热逆水煤气变换催化剂的性能受限于催化剂负载量、分散 性、稳定性的相互制约. 本文提出了一种核壳结构策略, 并以 $\mathrm{Ni}_{12} \mathrm{P}_{5}$ 为例, 设计了同时具有强光吸收、高分散度和高稳定性的光 热催化剂. 获得的 $\mathrm{Ni}_{12} \mathrm{P}_{5} @ \mathrm{SiO}_{2}$ 核壳结构催化剂在 $\mathrm{Ni}_{12} \mathrm{P}_{5}$ 负载量高达 $30 \mathrm{wt} \%$ 时, 依然保持了 $15 \mathrm{~nm}$ 的较小颗粒尺寸, 从而在光热催化逆 水煤气变换反应中表现出了更高的活性、接近 $100 \%$ 的 CO选择性 和极佳的稳定性, 尤其是在强光照条件下性能更加突出. 本研究揭 示了核壳策略能有效突破传统负载型催化剂的局限, 提高光热催 化 $\mathrm{CO}_{2}$ 还原的性能. 